\title{
Short-term postoperative outcomes following robotic versus laparoscopic ileal pouch-anal anastomosis are equivalent
}

\author{
A. L. Lightner ${ }^{1,3} \cdot$ F. Grass ${ }^{1} \cdot$ N. P. McKenna ${ }^{1} \cdot$ M. Tilman ${ }^{1} \cdot$ A. Alsughayer ${ }^{1} \cdot$ S. R. Kelley ${ }^{1} \cdot$ K. Behm $^{1} \cdot$ A. Merchea ${ }^{2}$. \\ D. W. Larson ${ }^{1}$
}

Received: 18 November 2018 / Accepted: 17 February 2019 / Published online: 2 April 2019

(c) Springer Nature Switzerland AG 2019

\begin{abstract}
Background Minimally invasive approaches have become the standard of care for ileal pouch-anal anastomoses (IPAA). There are few reports comparing outcomes following a laparoscopic versus robotic approach. Our aim was to determine if there were any differences in the 30-day postoperative outcomes following IPAA performed laparoscopically versus robotically.

Methods A retrospective chart review of all laparoscopic and robotic IPAA performed between January 1, 2015 and June 30, 2018 was carried out. Patients included were adult patients who underwent a proctectomy and IPAA utilizing either a laparoscopic or robotic approach. Data collected included patient demographics, operative variables, and 30-day postoperative outcomes.

Results A total of 132 patients had a minimally invasive IPAA; 58 were performed laparoscopically and 74 robotically. Less than half the patients were female $(n=55 ; 41.7 \%)$ with a median age of 37 years (range $18-68$ years). The majority of patients had a diagnosis of ulcerative colitis $(n=103 ; 78.0 \%)$ with medically refractory disease $(n=87 ; 65.9 \%)$. A greater proportion of patients in the laparoscopic cohort had a prolonged length of stay $(n=27 ; 46.6 \%$ versus $n=18 ; 24.3 \% ; p<0.001)$ and a two-stage approach $(n=56 ; 96.6 \%$ versus $n=37 ; 50 \% ; p<0.001)$, but there were no differences in the rates between the laparoscopic versus robotic cohorts of superficial surgical site infection $(6.9 \%$ versus $6.8 \% ; p=0.99)$, peripouch abscess (15.5\% versus $6.8 \% ; p=0.11$ ), anastomotic leak (6.9\% versus $2.7 \% ; p=0.21)$, pelvic abscess $(15.5 \%$ versus $6.8 \% ; p=0.11)$, and pelvic sepsis $(15.5 \%$ versus $6.8 \% ; p=0.11)$, readmission $(24.1 \%$ versus $17.6 \% ; p=0.35)$ or reoperation $(6.9 \%$ versus $5.4 \% ; p=0.72$ ). On multivariable analysis, only male sex remained predictive of prolonged length of stay, and a robotic approach trended toward a decreased rate of prolonged length of stay.

Conclusions Laparoscopic and robotic IPAA have equivalent postoperative morbidity underscoring the safety of the continued expansion of the robotic platform for pouch surgery.
\end{abstract}

Keywords Ileal pouch-anal anastomosis $\cdot$ Proctocolectomy $\cdot$ Restorative $\cdot$ Minimally invasive surgery $\cdot$ Robotic surgical procedures

\section{Introduction}

A restorative proctocolectomy with ileal pouch-anal anastomosis (IPAA) is the surgical treatment of choice for ulcerative colitis (UC) and familial adenomatous polyposis

A. L. Lightner Lightna@ccf.org (FAP) $[1,2]$. Since the advent of IPAA in 1978, the operative approach has evolved from only an open technique to

Division of Colon and Rectal Surgery, Mayo Clinic, Rochester, MN, USA

2 Division of Colon and Rectal Surgery, Mayo Clinic, Jacksonville, FL, USA

3 Colorectal Surgery, Cleveland Clinic, 9500 Euclid Ave, Cleveland, OH 44195, USA a variety of minimally invasive approaches including either hand assisted or straight laparoscopy, a transanal pelvic dissection with a single stapled anastomotic technique, or a robotic platform [3-5]. The evolution toward a less invasive approach has largely been driven by the clear patient 
benefits including a shorter length of postoperative stay [6, 7], improved body image [8], decreased infertility rates [9, 10], and decreased intravenous narcotic use [6].

Despite these advantages of conventional laparoscopy [11], there are also several limitations including reduced degrees of freedom of movement within the bony confines of the pelvis, poor visibility when performing the distal rectal dissection and subsequent ileal pouch anastomosis, and the need for an open incision to construct the IPAA. To overcome these limitations, some surgeons have begun using a transanal proctectomy with a single stapled anastomosis [3-5, 12], and others having begun using the robotic platform [13-15].

The Da Vinci ${ }^{\circledR}$ Surgical System (Intuitive Surgical, Mountain View, Sunnyvale, CA, USA) is being increasingly used for operations in colorectal surgery $[16,17]$. The improved dexterity, visualization, and ergonomics of the robotic platform, and extensive body of literature reporting equivalent safety and efficacy outcomes as compared to conventional laparoscopy, has contributed to the surge in its use for rectal cancer [18, 19]. The same advantages are seen using the robotic platform for IPAA, where it allows improved visualization during the distal rectal dissection to preserve the neurovascular structures in the pelvis, as well as during the intracorporeal double stapled anastomotic technique for the IPAA. These proposed advantages may outweigh the potential increased cost [20] and limitations related to lack of haptic feedback [21, 22]. In fact, early literature suggests this technique is feasible and has comparable outcomes to both open and laparoscopic approaches $[13,14]$. Due to its expanding use of the robotic platform for IPAA, we sought to compare the 30-day outcomes among patients undergoing a laparoscopic IPAA versus robotic IPAA to understand if a robotic approach is (1) associated with a reduced rate of 30-day postoperative complications, readmission and reoperation or (2) a reduced length of hospital stay.

\section{Materials and methods}

\section{Patients}

Following Institutional Review Board approval, all adult patients (age $\geq 18$ years) with UC, indeterminate colitis (IC), or FAP who had a laparoscopic or robotic IPAA between January 1, 2015 and June 30, 2018 were identified using a prospectively maintained pouch database. Hand assisted laparoscopy was defined as performing the proctectomy through a hand port and pouch in an open fashion; straight laparoscopy was defined as performing the majority of the proctectomy laparoscopically followed by a Pfannenstiel or lower midline incision to construct the pouch anastomosis; robotic was defined as performing the proctectomy robotically and the anastomosis intracorporeally under direct visualization. The following current procedural terminology (CPT) codes were used to identify cases from the database: 44157, 44158, and 44211, 45113. As there are currently no CPT codes specific to robotic surgery versus laparoscopic surgery, laparoscopic operative reports were individually read for the type of case performed to identify the use of the robotic platform.

Data collected included patient demographics [age, sex, body mass index (BMI)], smoking status, duration of disease, indication for operation, American Society of Anesthesiologists (ASA) score, diabetes mellitus (DM), preoperative clinical variables [serum laboratory values within 2 weeks prior to surgery and exposure to immunosuppressive medications preoperatively (corticosteroids and/or immunomodulators within 4 weeks of surgery, and anti-TNF, vedolizumab, or ustekinumab within 12 weeks of surgery)], operative characteristics (number of stages, anastomotic technique, operation length, estimated blood loss), and 30-day postoperative outcomes. The primary endpoint was the rate of 30-day postoperative complications including superficial surgical site infection (sSSI) defined as need to open the incision or prescribe antibiotics, peripouch abscess seen on abdominopelvic imaging, anastomotic leak seen on abdominopelvic imaging or upon return to the operating room, pelvic sepsis (composite of both abscess and/or anastomotic leak), urinary tract infection (UTI) defined by a positive urinary culture, venous thromboembolism (VTE), ileus (defined as need for insertion of nasogastric tube), and small bowel obstruction (SBO) as defined by need for reoperation. Secondary endpoints were length of stay after the initial operation, and the 30-day rate of reoperation, unplanned hospital readmission, and pelvic sepsis. Prolonged length was defined as a stay greater than the 75th percentile of the entire cohort, which was 6 days.

\section{Statistical analysis}

Summary statistics are presented as frequencies and percentages for categorical variables and median and interquartile ranges for continuous variables. Univariate analysis was performed using unequal variance $t$ tests for continuous variables and Pearson's Chi-squared tests for categorical variables. Univariate logistic regression analysis of potential risk factors for complications including laparoscopic versus robotic platform, gender, ASA, BMI, smoking, and diabetes was also performed. Additionally, the sample was separated by preoperative diagnosis of FAP or UC and the univariate logistic regression analysis was again performed based on either a laparoscopic or a robotic approach. Multivariate logistic regression analysis of prolonged length of stay included the following risk factors laparoscopic versus 
robotic surgery, gender, and n-stage. Significance was set at $p \leq 0.05$. Data analysis was performed using SAS 9.4 software (Institute, Cary, NC,USA).

\section{Results}

A total of 132 patients had a minimally invasive IPAA; 58 were performed laparoscopically and 74 robotically. Less than half the patients were female ( $n=55 ; 41.7 \%)$ with a median age of 37 years (range $18-68$ years). The majority of patients had a diagnosis of UC $(n=103 ; 78 \%)$; a minority were taking corticosteroids $(n=18 ; 13.6 \%)$, immunomodulators $(n=7 ; 5.3 \%)$ or biologics $(n=15$; $11.4 \%)$ for their medically refractory disease $(n=87$; $65.9 \%$ ). The median hemoglobin level was $13.0 \mathrm{mg} / \mathrm{dL}$ (range 11.0-14.0 mg/dL), median leukocytes was $7.4 \mathrm{mg}$ / $\mathrm{dL}$ (range 5.9-9.1 mg/dL), median platelet count was
$273 \times 10^{9} / \mathrm{L}$ (range $238-32010^{9} / \mathrm{L}$ ), median albumin level $4.4 \mathrm{~g} / \mathrm{dL}$ (range 4.0-4.6 g/dL), and median C-reactive protein level $4.4 \mathrm{mg} / \mathrm{L}$ (range4.0-4.6 g/dL). There was a significantly greater proportion of patients with FAP in the laparoscopic cohort as well as more patients having IPAA for dysplasia and polyposis. There were no significant differences in the laparoscopic versus robotic group with regard to age, sex, ASA, BMI, smoking status, DM, preoperative immunosuppressive regimens, or serum laboratory values (Table 1 ).

The majority of the cases were performed with a twostage approach $(n=93 ; 70.5 \%)$. In the majority of laparoscopic cases a lower midline incision was used for the anastomosis $(n=40 ; 69 \%)$ compared to a Pfannenstiel incision $(n=18 ; 31 \%)$. The robotic cohort had a significantly longer operating time than laparoscopic (315 min versus $281 \mathrm{~min} ; p<0.001)$, but a lower estimated blood loss (75 mL versus $100 \mathrm{~mL} ; p<0.001$ ) (Table 2).

Table 1 Demographics, preoperative treatments, and laboratory values

\begin{tabular}{|c|c|c|c|c|}
\hline & All patients $(n=132)$ & Robotic $(n=74)$ & Laparoscopic $(n=58)$ & $p$ \\
\hline Age (years), median (IQR) & $37(28-50)$ & $40(30-50)$ & $36(26-48)$ & 0.20 \\
\hline Gender (female) $(\%)$ & $55(41.7)$ & $29(39.2)$ & $26(44.8)$ & 0.51 \\
\hline $\mathrm{BMI}\left(\mathrm{kg} / \mathrm{m}^{2}\right)($ mean $\pm \mathrm{SD})$ & $24.6 \pm 4.7$ & $24.5 \pm 3.9$ & $24.8 \pm 5.7$ & 0.73 \\
\hline ASA group & & & & 0.63 \\
\hline $1(\%)$ & $7(5.3)$ & $4(5.4)$ & $3(5.2)$ & \\
\hline $2(\%)$ & $90(68.2)$ & $48(46.9)$ & $42(72.4)$ & \\
\hline $3(\%)$ & $35(26.5)$ & $22(29.7)$ & $13(22.4)$ & \\
\hline Diagnosis & & & & $<0.001$ \\
\hline Ulcerative colitis/Indeterminate colitis $(\%)$ & $104(78.8)$ & $67(91.9)$ & $36(62.1)$ & \\
\hline FAP $(\%)$ & $28(21.2)$ & $6(8.1)$ & $22(37.9)$ & \\
\hline Indication & & & & $<0.001$ \\
\hline Medically refractory $(\%)$ & $87(65.9)$ & $59(79.7)$ & $28(48.3)$ & \\
\hline Dysplasia/adenocarcinoma (\%) & $24(18.2)$ & $10(13.5)$ & $14(24.1)$ & \\
\hline Polyposis (\%) & $21(15.9)$ & $5(6.8)$ & $16(27.6)$ & \\
\hline Smoking (\%) & $9(6.8)$ & $3(4.1)$ & $6(10.3)$ & 0.15 \\
\hline Diabetes $(\%)$ & $5(4.8)$ & $3(4.1)$ & $2(3.4)$ & 0.86 \\
\hline Preoperative steroids (\%) & $18(13.6)$ & $9(12.2)$ & $9(15.5)$ & 0.58 \\
\hline Preoperative IMM (\%) & $7(5.3)$ & $2(2.7)$ & $5(8.6)$ & 0.13 \\
\hline Preoperative biologics (\%) & $15(11.4)$ & $8(10.8)$ & $7(12.1)$ & 0.82 \\
\hline Preoperative hemoglobin $(\mathrm{g} / \mathrm{dL})$ & $13(11-14)$ & $12(11-14)$ & $13(12-15)$ & 0.08 \\
\hline Preoperative leukocyte count $\left(\times 10^{9} / \mathrm{L}\right)$ & $7.4(5.9-9.1)$ & $7.4(5.6-9.3)$ & $7.8(6.3-9.1)$ & 0.80 \\
\hline Preoperative platelet count $\left(\times 10^{9} / \mathrm{L}\right)$ & $273(238-320)$ & $228(236-315)$ & $278(239-362)$ & 0.49 \\
\hline Preoperative albumin (g/L) & $4.4(4-4.6)$ & $4.4(4.1-4.5)$ & $4.4(4-4.6)$ & 0.37 \\
\hline Preoperative CRP (mg/L) & $4.4(4-4.6)$ & $4.4(4.1-4.5)$ & $4.4(4-4.6)$ & 0.37 \\
\hline
\end{tabular}

Laboratory values expressed as median (IQR)

Bold characters indicate significant values $(p<0.05)$

Baseline demographics, preoperative treatments and preoperative laboratory values of patients undergoing laparoscopic IPAA $(n=58)$ and patients undergoing robotic IPAA $(n=74)$

$I Q R$ interquartile range, BMI body mass index, ASA American Society of Anesthesiology, FAP familial adenomatous polyposis, IMM immunomodulator, $C R P$ C-reactive protein 
Table 2 Operative characteristics

\begin{tabular}{lllcl}
\hline & All patients $(n=132)$ & Robotic $(n=74)$ & Laparoscopic $(n=58)$ & $p$ \\
\hline$n$ stages & & & & \\
$2(\%)$ & $93(70.5)$ & $37(50)$ & $56(96.6)$ & $<\mathbf{0 . 0 0 1}$ \\
$3(\%)$ & $39(29.5)$ & $37(50)$ & $2(3.4)$ & \\
$\begin{array}{l}\text { Operating time } \\
\quad \text { minutes), }\end{array}$ & $314(252-349)$ & $315(276-365)$ & $281(235-335)$ & $\mathbf{0 . 0 0 2}$ \\
$\quad \begin{array}{l}\text { median (IQR) } \\
\begin{array}{l}\text { Estimated blood } \\
\text { loss(ml), } \\
\text { median (IQR) }\end{array}\end{array}$ & $75(50-100)$ & $75(50-100)$ & $100(50-175)$ & $\mathbf{0 . 0 0 2}$ \\
\hline
\end{tabular}

Operative characteristics of patients undergoing laparoscopic IPAA $(n=58)$ and patients undergoing robotic IPAA $(n=74)$

Bold characters indicate significant values $(p<0.05)$
A greater proportion of patients in the laparoscopic cohort had a prolonged length of stay $(n=27 ; 46.6 \%$ versus $n=18$; $24.3 \% ; p=0.01)$. There were no differences in the rates of ileus or small bowel obstruction, for which the overall rates were $18 \%$ and $3 \%$, respectively. There were no differences between the laparoscopic and robotic cohorts in the rates of superficial SSI (6.9\% versus $6.8 \% ; p=0.98)$, peripouch abscess $(15.5 \%$ versus $6.8 \%$; $p=0.11)$, anastomotic leak $(6.9 \%$ versus $2.7 \%$; $p=0.21)$, pelvic abscess $(15.5 \%$ versus $6.8 \% ; p=0.11)$, and pelvic sepsis $(15.5 \%$ versus $6.8 \%$; $p=0.11)$. Thirty-day intensive care unit admission, $(2.7 \%$ versus $1.7 \% ; p=0.72$ ) readmission $(24.1 \%$ versus $17.6 \%$; $p=0.35)$ or reoperation $(6.9 \%$ versus $5.4 \% ; p=0.72)$ rates were also not significantly different in the two cohorts (Table 3).
Univariate logistic regression for the 30-day postoperative outcome variables including ileus, superficial SSI, peripouch abscess, anastomotic leak, pelvic sepsis, reoperation, and readmission did not identify any significant associations for each outcome considered. Laparoscopic approach, male sex and a 2 stage IPAA were all associated with a prolonged length of stay ( $p=0.01$ ) (Table 4). On multivariable analysis for prolonged length of stay, only male sex remained significant $(p<0.01)$ (Table 5).
Table 3 30-Day postoperative outcomes

\begin{tabular}{lclll}
\hline & All patients $(n=132)$ & Robotic $(n=74)$ & $\begin{array}{l}\text { Laparo- } \\
\text { scopic } \\
(n=58)\end{array}$ & P \\
\hline Ileus (\%) & $24(18.2)$ & $11(14.9)$ & $13(22.4)$ & 0.2644 \\
SBO (\%) & $4(3)$ & $4(5.4)$ & 0 & 0.0722 \\
Superficial SSI (\%) & $9(6.8)$ & $5(6.8)$ & $4(6.9)$ & 0.9748 \\
Peripouch abscess (\%) & $14(10.6)$ & $5(6.8)$ & $9(15.5)$ & 0.1047 \\
Anastomotic leak (\%) & $6(4.5)$ & $2(2.7)$ & $4(6.9)$ & 0.2509 \\
Pelvic sepsis (\%) & $14(10.6)$ & $5(6.8)$ & $4(6.9)$ & 0.1047 \\
UTI (\%) & $2(1.5)$ & 0 & $2(3.4)$ & 0.1075 \\
VTE (\%) & $2(1.5)$ & $2(2.7)$ & 0 & 0.2071 \\
30-day ICU admission (\%) & $3(2)$ & $2(3)$ & $1(2)$ & 0.7081 \\
Readmission (\%) & $27(20.5)$ & $13(17.6)$ & $14(24.1)$ & 0.3530 \\
Reoperation (\%) & $8(6.1)$ & $4(5.4)$ & $4(6.9)$ & 0.7216 \\
Length of stay (days), median (IQR) & $5(3-6)$ & $4(3-5)$ & $5(4-7)$ & 0.0503 \\
Prolonged stay (\%) & $45(34.1)$ & $18(24.3)$ & $27(46.6)$ & $\mathbf{0 . 0 0 7 5}$ \\
\hline
\end{tabular}

30-day complications of patients undergoing laparoscopic IPAA $(n=58)$ and patients undergoing robotic IPAA $(n=74)$

Bold characters indicate significant values $(p<0.05)$

$S B O$ small bowel obstruction, SSI surgical site infection, UTI urinary tract infection, VTE venous thromboembolism, $I C U$ intensive care unit, $I Q R$ interquartile range 
Table 4 Logistic regression for discrete outcome variables

\begin{tabular}{|c|c|c|c|c|c|}
\hline \multirow[t]{2}{*}{ Dependent variable } & \multirow[t]{2}{*}{ Variable } & \multirow[t]{2}{*}{ OR } & \multicolumn{2}{|c|}{$95 \% \mathrm{CI}$} & \multirow[t]{2}{*}{$p$} \\
\hline & & & Lower & Upper & \\
\hline \multirow[t]{9}{*}{ Ileus } & Laparoscopic & 1.66 & 0.68 & 4.03 & 0.27 \\
\hline & Male gender & 1.00 & 0.41 & 2.45 & 1.00 \\
\hline & ASA & 1.42 & 0.61 & 3.31 & 0.41 \\
\hline & BMI & 1.09 & 1.00 & 1.20 & 0.06 \\
\hline & Smoking & 0.54 & 0.07 & 4.56 & 0.57 \\
\hline & Diabetes & 3.18 & 0.50 & 20.18 & 0.22 \\
\hline & n stages & 0.42 & 0.13 & 1.31 & 0.14 \\
\hline & Diagnosis-UC & 2.55 & 0.96 & 6.78 & 0.06 \\
\hline & Diagnosis-FAP & 0.50 & 0.04 & 6.68 & 0.60 \\
\hline \multirow[t]{9}{*}{ Superficial SSI } & Laparoscopic & 1.02 & 0.26 & 3.99 & 0.97 \\
\hline & Male gender & 1.46 & 0.35 & 6.13 & 0.60 \\
\hline & ASA & 1.60 & 0.45 & 5.74 & 0.47 \\
\hline & BMI & 1.06 & 0.93 & 1.21 & 0.40 \\
\hline & Smoking & 1.80 & 0.20 & 16.20 & 0.60 \\
\hline & Diabetes & 0.88 & 0.04 & 22.53 & 0.98 \\
\hline & n stages & 0.66 & 0.13 & 3.35 & 0.62 \\
\hline & Diagnosis-UC & 1.58 & 0.40 & 6.27 & 0.52 \\
\hline & Diagnosis-FAP & - & - & - & - \\
\hline \multirow[t]{9}{*}{ Pelvic abscess } & Laparoscopic & 2.54 & 0.80 & 8.03 & 0.11 \\
\hline & Male gender & 1.32 & 0.42 & 4.19 & 0.63 \\
\hline & ASA & 1.01 & 0.35 & 2.91 & 0.99 \\
\hline & BMI & 1.06 & 0.95 & 1.19 & 0.29 \\
\hline & Smoking & 1.06 & 0.12 & 9.14 & 0.96 \\
\hline & Diabetes & 2.19 & 0.23 & 21.12 & 0.50 \\
\hline & n stages & 1.37 & 0.43 & 4.39 & 0.54 \\
\hline & Diagnosis-UC & 3.04 & 0.89 & 10.40 & 0.08 \\
\hline & Diagnosis-FAP & 1.59 & 0.05 & 46.78 & 0.96 \\
\hline \multirow[t]{9}{*}{ Reoperation } & Laparoscopic & 1.30 & 0.31 & 5.42 & 0.72 \\
\hline & Male gender & 0.70 & 0.17 & 2.92 & 0.62 \\
\hline & ASA & 1.86 & 0.48 & 7.18 & 0.37 \\
\hline & BMI & 0.94 & 0.80 & 1.11 & 0.48 \\
\hline & Smoking & 2.07 & 0.23 & 18.97 & 0.52 \\
\hline & Diabetes & 0.78 & 0.03 & 20.15 & 0.98 \\
\hline & n stages & 0.78 & 0.15 & 4.07 & 0.52 \\
\hline & Diagnosis-UC & 2.00 & 0.47 & 8.52 & 0.35 \\
\hline & Diagnosis-FAP & - & - & - & - \\
\hline \multirow{9}{*}{$\begin{array}{l}\text { Prolonged length of } \\
\text { stay }\end{array}$} & Laparoscopic & 2.71 & 1.29 & 5.68 & 0.01 \\
\hline & Male gender & 2.69 & 1.23 & 5.88 & 0.01 \\
\hline & ASA & 1.74 & 0.87 & 3.50 & 0.12 \\
\hline & BMI & 1.05 & 0.97 & 1.13 & 0.20 \\
\hline & Smoking & 0.96 & 0.23 & 4.05 & 0.96 \\
\hline & Diabetes & 1.30 & 0.21 & 8.09 & 0.78 \\
\hline & n stages & 0.32 & 0.13 & 0.79 & 0.01 \\
\hline & Diagnosis-UC & 2.14 & 0.91 & 5.07 & 0.08 \\
\hline & Diagnosis-FAP & 6.00 & 0.60 & 60.14 & 0.13 \\
\hline
\end{tabular}

Table 4 (continued)

\begin{tabular}{|c|c|c|c|c|c|}
\hline \multirow[t]{2}{*}{ Dependent variable } & \multirow[t]{2}{*}{ Variable } & \multirow[t]{2}{*}{ OR } & \multicolumn{2}{|c|}{$95 \% \mathrm{CI}$} & \multirow[t]{2}{*}{$p$} \\
\hline & & & Lower & Upper & \\
\hline \multirow[t]{9}{*}{ Readmission } & Laparoscopic & 1.49 & 0.64 & 3.49 & 0.35 \\
\hline & Male gender & 0.60 & 0.25 & 1.39 & 0.23 \\
\hline & ASA & 1.05 & 0.47 & 2.35 & 0.9 \\
\hline & BMI & 1.00 & 0.91 & 1.09 & 0.9 \\
\hline & Smoking & 2.06 & 0.48 & 8.85 & 0.3 \\
\hline & Diabetes & 0.97 & 0.10 & 9.06 & 0.9 \\
\hline & n stages & 1.25 & 0.51 & 3.09 & 0.5 \\
\hline & Diagnosis-UC & 1.56 & 0.59 & 4.14 & 0.3 \\
\hline & Diagnosis-FAP & 1.47 & 0.14 & 15.68 & 0.7 \\
\hline \multirow[t]{9}{*}{ Pelvic sepsis } & Laparoscopic & 2.54 & 0.80 & 8.03 & 0.1 \\
\hline & Male gender & 1.32 & 0.42 & 4.19 & 0.6 \\
\hline & ASA & 1.01 & 0.35 & 2.91 & 0.99 \\
\hline & BMI & 1.06 & 0.95 & 1.19 & 0.29 \\
\hline & Smoking & 1.06 & 0.12 & 9.14 & 0.96 \\
\hline & Diabetes & 2.19 & 0.23 & 21.12 & 0.50 \\
\hline & n stages & 1.37 & 0.43 & 4.39 & 0.54 \\
\hline & Diagnosis-UC & 3.04 & 0.89 & 10.40 & 0.08 \\
\hline & Diagnosis-FAP & 1.59 & 0.05 & 46.78 & 0.9 \\
\hline
\end{tabular}

Bold characters indicate significant values $(p<0.05)$

ASA American Society of Anesthesiology, BMI body mass index, SSI surgical site infection

Table 5 Multivariable analysis for prolonged length of stay

\begin{tabular}{lllllr}
\hline Dependent variable & Variable & OR & \multicolumn{2}{l}{$95 \%$ CI } & \multirow{2}{*}{$p$} \\
\cline { 5 - 6 } & & & Lower & Upper & \\
\hline Prolonged Length of & Robotic & 0.44 & 0.18 & 1.07 & 0.07 \\
stay & Male gender & 3.00 & 1.32 & 6.83 & $<0.01$ \\
& N stages $=3$ & 0.49 & 0.17 & 1.42 & 0.19 \\
\hline
\end{tabular}

\section{Discussion}

Compared with conventional laparoscopy, we found that a robotic approach was associated with a clinically significant decrease in the rate of pelvic sepsis, with no change in other 30-day morbidity.

When laparoscopy was first applied to colon and rectal pathology, there was initial skepticism about its utility due to prolonged operative times and high conversion rates. However, widespread adoption has shortened operative times, and randomized controlled trials comparing laparoscopic versus open approaches for colon cancer have demonstrated faster recovery, decreased morbidity, and reduced hospital length of stay, and comparable oncological survival outcomes with a laparoscopic approach [27-29]. Laparoscopy does have limitations around the 
view available and freedom of movement; largely overcome using a robotic platform.

These advantages of the robotic approach in forming the IPAA may help reduce the rate of pelvic sepsis, which is the most dreaded complication of pouch surgery due to known increased rates of pouch failure $[9,12]$. Pelvic sepsis following original IPAA occurs in 5-25\% [1, 30-32] of patients, and most commonly is a result of a peripouch abscess or anastomotic leak from the pouch-anal staple line. This inflammation eventually leads to scarring and pelvic fibrosis, causing decreased distensibility of the pouch, which ultimately manifests as poor long-term pouch function or eventual need for pouch reconstruction [33]. With a robotic approach, one can visualize the dissection down to the pelvic floor, ensure the height of the rectal transection with regard to the levator ani muscles, and then perform the anastomosis intracorporeally under direct visualization, which improves the alignment of the stapler ends, pouch orientation and mesenteric orientation. This in turn means that technical contributors to leak are minimized and this may lead to a reduction the rate of pelvic sepsis. While underpowered, there was a trend towards decreased pelvic sepsis within this study. As more outcomes after robotic IPAA are reported, it will enable the determination of whether robotic IPAA should be the preferred approach when a difficult pelvic dissection and anastomosis is anticipated.

Using a transanal approach to the distal proctectomy and pouch anastomotic construction $[12,34]$ may allow an exact identification of where to transect the rectum for the anastomosis, and allow a single stapled rather than a double stapled technique thus avoiding crossing staple lines. While the transanal approach may be useful, the learning curve is steep, and it remains unknown if the anastomotic leak rate following IPAA is lowered.

There are few reports of robotic IPAA. Miller et al. [14] compared 17 robotic cases to 17 laparoscopic cases and found no differences in complications or short-term functional results. Interestingly the return to bowel function and the length of stay was longer in the robotic than the laparoscopic group. Rencuzagullari et al compared 21 robotic completion proctectomy cases to 21 laparoscopic proctectomy cases, with IPAA performed in 18 patients in each cohort, and found that the operative time and blood loss was higher in the robotic group, but that the length of stay and postoperative outcomes were similar in the two cohorts [35]. Mark-Christensen et al compared 81 robotic IPAA cases to 170 open IPAA cases and found no difference in the rate of postoperative complications but the robotic group did have an increased rate of readmission [13]. We found equivalent rates of postoperative morbidity in the laparoscopic and robotic cohorts.

Future research will be needed to gather larger numbers of patients treated by each minimally invasive approach to better answer whether one approach is better than another with regard to perioperative outcomes, functional outcomes, fertility outcomes, and quality of life outcomes. We anticipate that if lower leak rates are achieved with one particular approach functional outcomes will also be improved. Similarly, we anticipate less adhesion formation when using a technique that does not require an incision for pouch formation (a robotic platform or a transanal approach) versus even laparoscopy which uses an incision for the anastomotic construction. With less adhesions, we would anticipate that fertility would be improved. Similarly, without an incision, there is less risk of hernia formation, postoperative SBO, and need for future surgical intervention to address these complications. Longitudinal longer-term studies will be useful in determining whether these advantages are seen with these minimally invasive approaches.

There are several limitations to this study. First this is a retrospective review of a prospectively maintained database, limiting the analysis of postoperative outcomes. Second, we are an inflammatory bowel disease referral center and our patient population may be different from that of outside institutions, limiting the applicability of our findings. Third, many of our patients travel long distances. Therefore, we do not have routine postoperative visits, but often rely on patient phone calls and nursing communication to gather information on postoperative outcomes and complications. Thus, our 30-day complication rate may be under-reported. Fourth, there were not enough events for a multivariable analysis of pelvic sepsis to determine whether a robotic approach results in decreased rates of pelvic sepsis, which may then have implications on long term functional outcomes. Fifth, we do not yet have data on long-term functional outcomes following a robotic versus laparoscopic approach, which are arguably more significant than 30-day postoperative outcomes.

\section{Conclusions}

Laparoscopic and robotic IPAA have equivalent postoperative morbidity. The choice of operative instrument should be based on the individual surgeon's skill and preference, availability of technology, and any patient preferences. Since the application remains novel, we will have to wait for long-term prospective functional and quality of life data.

Author contributions All authors meet the three authorship criteria: substantial contribution, participation in drafting the article, and final approval.

Funding There are no sources of funding. 


\section{Compliance with ethical standards}

Conflict of interest Amy Lightner receives consultant fees from Take$\mathrm{da}$; all other authors: declare that they have no conflict of interest.

Ethical approval All human studies have been reviewed by the appropriate ethics committee and have therefore been performed in accordance with the ethical standards laid down in an appropriate version of the 1965 Declaration of Helsinki.

Informed consent For this type of study, informed consent was not necessary.

\section{References}

1. Fazio VW, Ziv Y, Church JM et al (1995) Ileal pouch-anal anastomoses complications and function in 1005 patients. Ann Surg 222(2):120-127

2. Parks AG, Nicholls RJ (1978) Proctocolectomy without ileostomy for ulcerative colitis. Br Med J 2(6130):85-88

3. Perdawood SK, Al Khefagie GA (2016) Transanal vs laparoscopic total mesorectal excision for rectal cancer: initial experience from Denmark. Colorectal Dis 18(1):51-58

4. Perdawood SK, Thinggaard BS, Bjoern MX (2018) Effect of transanal total mesorectal excision for rectal cancer: comparison of short-term outcomes with laparoscopic and open surgeries. Surg Endosc 32(5):2312-2321

5. Simillis C, Hompes R, Penna M, Rasheed S, Tekkis PP (2016) A systematic review of transanal total mesorectal excision: is this the future of rectal cancer surgery? Colorectal Dis 18(1):19-36

6. Larson DW, Cima RR, Dozois EJ et al (2006) Safety, feasibility, and short-term outcomes of laparoscopic ileal-pouch-anal anastomosis: a single institutional case-matched experience. Ann Surg 243(5):667-670 (discussion 670-662)

7. White I, Jenkins JT, Coomber R, Clark SK, Phillips RK, Kennedy RH (2014) Outcomes of laparoscopic and open restorative proctocolectomy. Br J Surg 101(9):1160-1165

8. Ahmed Ali U, Keus F, Heikens JT et al (2009) Open versus laparoscopic (assisted) ileo pouch anal anastomosis for ulcerative colitis and familial adenomatous polyposis. Cochrane Database Syst Rev. https://doi.org/10.1002/14651858.CD006267.pub2

9. Bartels SA, D'Hoore A, Cuesta MA, Bensdorp AJ, Lucas C, Bemelman WA (2012) Significantly increased pregnancy rates after laparoscopic restorative proctocolectomy: a cross-sectional study. Ann Surg 256(6):1045-1048

10. Beyer-Berjot L, Maggiori L, Birnbaum D, Lefevre JH, Berdah S, Panis Y (2013) A total laparoscopic approach reduces the infertility rate after ileal pouch-anal anastomosis: a 2-center study. Ann Surg 258(2):275-282

11. Baek SJ, Dozois EJ, Mathis KL et al (2016) Safety, feasibility, and short-term outcomes in 588 patients undergoing minimally invasive ileal pouch-anal anastomosis: a single-institution experience. Tech Coloproctol 20(6):369-374

12. de Buck van Overstraeten A, Mark-Christensen A, Wasmann KA et al (2017) Transanal versus transabdominal minimally invasive (completion) proctectomy with ileal pouch-anal anastomosis in ulcerative colitis: a comparative study. Ann Surg 266(5):878-883

13. Mark-Christensen A, Pachler FR, Norager CB, Jepsen P, Laurberg S, Tottrup A (2016) Short-term outcome of robot-assisted and open IPAA: an observational single-center study. Dis Colon Rectum 59(3):201-207

14. Miller AT, Berian JR, Rubin M, Hurst RD, Fichera A, Umanskiy K (2012) Robotic-assisted proctectomy for inflammatory bowel disease: a case-matched comparison of laparoscopic and robotic technique. J Gastrointest Surg 16(3):587-594

15. Roviello F, Piagnerelli R, Ferrara F, Scheiterle M, De Franco L, Marrelli D (2015) Robotic single docking total colectomy for ulcerative colitis: First experience with a novel technique. Int J Surg 21:63-67

16. Yang Y, Wang F, Zhang P et al (2012) Robot-assisted versus conventional laparoscopic surgery for colorectal disease, focusing on rectal cancer: a meta-analysis. Ann Surg Oncol 19(12):3727-3736

17. Juo YY, Hyder O, Haider AH, Camp M, Lidor A, Ahuja N (2014) Is minimally invasive colon resection better than traditional approaches?: First comprehensive national examination with propensity score matching. JAMA Surg 149(2):177-184

18. Trinh BB, Jackson NR, Hauch AT, Hu T, Kandil E (2015) Robotic versus laparoscopic colorectal surgery. J Soc Laparoendosc Surg 18(4):e2014.00187. https://doi.org/10.4293/ JSLS.2014.00187

19. Kim MJ, Park SC, Park JW et al (2018) Robot-assisted versus laparoscopic surgery for rectal cancer: a phase II open label prospective randomized controlled trial. Ann Surg 267(2):243-251

20. Tyler JA, Fox JP, Desai MM, Perry WB, Glasgow SC (2013) Outcomes and costs associated with robotic colectomy in the minimally invasive era. Dis Colon Rectum 56(4):458-466

21. Rawlings AL, Woodland JH, Vegunta RK, Crawford DL (2007) Robotic versus laparoscopic colectomy. Surg Endosc 21(10):1701-1708

22. Bertani E, Chiappa A, Biffi R et al (2011) Assessing appropriateness for elective colorectal cancer surgery: clinical, oncological, and quality-of-life short-term outcomes employing different treatment approaches. Int J Colorectal Dis 26(10):1317-1327

23. Zhang H, Hu S, Zhang G et al (2007) Laparoscopic versus open proctocolectomy with ileal pouch-anal anastomosis. Minim Invasive Ther Allied Technol 16(3):187-191

24. Fajardo AD, Dharmarajan S, George V et al (2010) Laparoscopic versus open 2-stage ileal pouch: laparoscopic approach allows for faster restoration of intestinal continuity. J Am Coll Surg 211(3):377-383

25. Duff SE, Sagar PM, Rao M, Macafee D, El-Khoury T (2012) Laparoscopic restorative proctocolectomy: safety and critical level of the ileal pouch anal anastomosis. Colorectal Dis 14(7):883-886

26. Mak TW, Lee JF, Futaba K, Hon SS, Ngo DK, Ng SS (2014) Robotic surgery for rectal cancer: a systematic review of current practice. World J Gastrointest Oncol 6(6):184-193

27. Guillou PJ, Quirke P, Thorpe H et al (2005) Short-term endpoints of conventional versus laparoscopic-assisted surgery in patients with colorectal cancer (MRC CLASICC trial): multicentre, randomised controlled trial. Lancet 365(9472):1718-1726

28. Jayne D, Pigazzi A, Marshall H et al (2017) Effect of roboticassisted vs conventional laparoscopic surgery on risk of conversion to open laparotomy among patients undergoing resection for rectal cancer: the ROLARR randomized clinical trial. JAMA 318(16):1569-1580

29. Lacy AM, Delgado S, Castells A et al (2008) The long-term results of a randomized clinical trial of laparoscopy-assisted versus open surgery for colon cancer. Ann Surg 248(1):1-7

30. Ross H, Steele SR, Varma M et al (2014) Practice parameters for the surgical treatment of ulcerative colitis. Dis Colon Rectum 57(1):5-22

31. Kiely JM, Fazio VW, Remzi FH, Shen B, Kiran RP (2012) Pelvic sepsis after IPAA adversely affects function of the pouch and quality of life. Dis Colon Rectum 55(4):387-392

32. Selvaggi F, Sciaudone G, Limongelli P et al (2010) The effect of pelvic septic complications on function and quality of life after ileal pouch-anal anastomosis: a single center experience. Am Surg 76(4):428-435 
33. Heuschen UA, Allemeyer EH, Hinz U, Lucas M, Herfarth C, Heuschen G (2002) Outcome after septic complications in J pouch procedures. Br J Surg 89(2):194-200

34. Leo CA, Samaranayake S, Perry-Woodford ZL et al (2016) Initial experience of restorative proctocolectomy for ulcerative colitis by transanal total mesorectal rectal excision and single-incision abdominal laparoscopic surgery. Colorectal Dis 18(12):1162-1166

35. Rencuzogullari A, Gorgun E, Costedio M et al (2016) Casematched comparison of robotic versus laparoscopic proctectomy for inflammatory bowel disease. Surg Laparosc Endosc Percutan Tech 26(3):e37-e40

Publisher's Note Springer Nature remains neutral with regard to jurisdictional claims in published maps and institutional affiliations. 